Results: 1525 (73\%) patients answered the pain questions in 2010 and 1046 $(68 \%)$ in 2017 . In all 950 of the patients answered the questions at both time points and were included in the study. One third (324) of the patients had reported, CWP in 2010 and 140 (43\%) of the patients with CWP in 2010 had improved in 2017. The patients, who improved, had lower BMI, $p=0.045$, less tender joint counts, $p=0.007$, less pain, $p=0.005$, less fatigue, $p<0.001$ and less painful regions, $p<0.001$, better PatGA, $p=0.002$, better $H A Q, p<0.001$ and better $E Q-5 D$, $\mathrm{p}=0.003$. Fifty-five percent of the patients who improved were treated with DMARD, compared to $52 \%$ of those not improving, the rate treated with biologics were $32 \%$ vs. $26 \%$. There were, however, no statistical significant difference in medical treatment between the groups, $\mathrm{p}=0.088$.

Age and sex adjusted logistic regression models showed an increased chance for improvement from CWP in patients with normal BMI, less TJC, pain, fatigue and tender regions and better PatGA, HAQ and EQ-5D, table 1. Biologic treatment also increased the chances to improve from CWP. The most common biologic treatment was anti-TNF treatment. Of the patients, who were treated with biologics, $86 \%$ in the group, who improved from CWP and $74 \%$ in the group, who did not improve, were treated with anti-TNF treatment. Age, gender, smoking habits, SJC and glucocorticoid treatment were not associated with improvement in the model.

Abstract FRI0076 - Table 1. A crude logistic regression model were the data were age and sex adjusted, except age, which was adjusted for sex and sex, adjusted for age.

\begin{tabular}{llll}
\hline & & OR & $95 \% \mathrm{Cl}$ \\
\hline Age 2010 & & 1.011 & $0.992-1.031$ \\
Gender & women & 0.960 & $0.542-1.702$ \\
Smoking habits 2010 & Smoker & 0.580 & $0.282-1.195$ \\
& Previous smoker & 0.793 & $0.479-1.311$ \\
BMI 2010 & $<18,5$ & 0.320 & $0.037-2.930$ \\
& $18,5-24,9$ & 2.146 & $1.121-4.106$ \\
& $25-29,9$ & 1.294 & $0.708-2.365$ \\
TJC 2010 & $<7$ & 1.798 & $1.148-2.815$ \\
SJC 2010 & $<4$ & 1.477 & $0.943-2.312$ \\
PatGA 2010 & $<4$ & 1.806 & $1.146-2.848$ \\
Pain 2010 & $<5$ & 1.836 & $1.164-2.898$ \\
Fatigue 2010 & $<6$ & 3.249 & $\mathbf{2 . 0 1 3 - 5 . 2 4 6}$ \\
EQ5D 2010 & $\geq 0.725$ & 2.092 & $1.318-3.3821$ \\
HAQ 2010 & $<0.75$ & 1.988 & $1.246-3.173$ \\
Total pain regions 2010 & $<8$ & 2.987 & $1.888-4.727$ \\
Medical treatment 2010 & DMARD & 1.779 & $0,940-3.366$ \\
& Biologics & 2.202 & $1.099-4.413$ \\
Prednisolone treatment 2010 & Pred & 0.753 & $0.448-1.265$ \\
\hline
\end{tabular}

Conclusions: Lower scores in pain related variables and fatigue, normal BMI, better physical function and health-related quality of life, and biologic treatment were associated to improvement from CWP in patients with RA. Knowledge of factors associated to improvement from CWP could be helpful when treating RA patients with CWP. More studies with focus on improvement from chronic pain in patients with RA are needed.

Disclosure of Interest: None declared

DOI: 10.1136/annrheumdis-2018-eular.2922

\section{FRI0077 HEPATITIS B VIRUS REACTIVATION IN PATIENTS WITH RHEUMATOID ARTHRITIS TREATED WITH BARICITINIB: POST-HOC ANALYSIS FROM CLINICAL TRIALS}

M. Harigai ${ }^{1}$, K. Winthrop ${ }^{2}$, T. Takeuchi ${ }^{3}$, T.-Y. Hsieh ${ }^{4}$, Y.-M. Chen ${ }^{4}$, J.S. Smolen ${ }^{5}$,

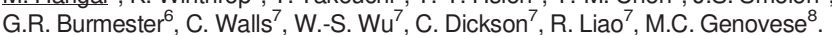
${ }^{1}$ Tokyo Women's Medical Univ, Tokyo, Japan; ${ }^{2}$ Oregon Health Sciences Univ, Portland, USA; ${ }^{3}$ Keio University, Tokyo, Japan; ${ }^{4}$ Taichung Veterans General Hospital, Taichung, Taiwan, Province of China; ${ }^{5}$ Medical Univ of Vienna, Vienna, Austria; ${ }^{6}$ Charite Universitatsmedizin Berlin, Berlin, Germany; ${ }^{7}$ Eli Lilly and Company, Indianapolis; ${ }^{8}$ Stanford Univ, Palo Alto, USA

Background: Baricitinib (BARI) is an oral selective Janus kinase (JAK)1 and JAK2 inhibitor approved in the EU, Japan, and other countries for treatment of moderately to severely active rheumatoid arthritis (RA) in adults. RA therapies may increase risk of hepatitis $B$ virus (HBV) infection ${ }^{1}$. HBV reactivation is a concern in previously infected patients (pts), including those with serologic evidence of resolution. HBV exposure is common in many Asian countries. ${ }^{2}$ Limited data exist on HBV reactivation among pts with RA treated with JAK inhibitors.

Objectives: To assess HBV reactivation in pts with RA treated with BARI during Phase $(\mathrm{Ph}) 3$ trials.
Methods: At screening, all pts were tested for HBV surface antigen (HBsAg), core antibody ( $\mathrm{HBcAb}$ ) and surface antibody (HBsAb). In Japan and elsewhere if required, pts had screening HBV DNA tests. Pts were excluded if they had 1 ) $\mathrm{HBsAg}+$, 2) $\mathrm{HBcAb}+\mathrm{HBsAb}$ - (in Japan, could enrol if HBV DNA-), or 3) HBsAb +and HBV DNA+. Routine HBV DNA monitoring was performed in Japan for pts with $\mathrm{HBcAb}+$ and/or $\mathrm{HBsAb}+$ at screening, and was later instituted globally for $\mathrm{HBcAb}+$ pts. Pts with post-baseline HBV DNA+ $(\geq 29 \mathrm{IU} / \mathrm{mL})$ were discontinued from the study and referred to a hepatologist. In select cases, investigators continued study drug following a HBV DNA +test in consultation with the sponsor and in accordance with HBV management guidelines. Data were integrated from $4 \mathrm{com}-$ pleted $\mathrm{Ph} 3$ trials and 1 ongoing long-term extension (LTE) (data to April 2017). Results: Of 2890 pts with $\geq 1$ dose of BARI (6993 pt-years exposure), 269 pts had baseline serology suggestive of prior infection ( $\mathrm{HBcAb}+/ \mathrm{HBsAb+}, \mathrm{n}=255$ $\mathrm{HBCAb+/HBsAb-,} n=14$ ) (figure 1). Post-baseline HBV DNA tests were performed for 290 pts (including some pts without a baseline HBV DNA result). After BARI initiation, 7 of 201 pts (3\%) with $\mathrm{HBcAb}+/ \mathrm{HBsAb}+$ at baseline had quantifiable HBV DNA +levels ( $>29 \mathrm{IU} / \mathrm{mL}$; median 256, range 31-1547 IU/mL). An additional 23 (11\%) had qualitative HBV DNA +results below the lower limit of detection (LLD) ( $<29 \mathrm{IU} / \mathrm{mL}$ ). Of these $30 \mathrm{HBcAb}+/ \mathrm{HBsAb}+$ pts with HBV DNA +tests post-baseline, 22 had HBV DNA- tests at baseline. Among 14 pts with $\mathrm{HBcAB}+/ \mathrm{HBs} A b-$, all had HBV DNA- tests at baseline; repeat HBV DNA test results post-baseline were quantifiable (1 at $36 \mathrm{IU} / \mathrm{mL}$ ), below the LLD, ${ }^{1}$ and undetectable. ${ }^{12}$ Of pts with quantifiable HBV DNA, adverse events (AE) of detectable HBV DNA resulted in discontinuation of 4 of 8 pts of whom 3 received antivirals. 4 of 8 pts continued BARI in the LTE and have not received antivirals. All pts with quantifiable HBV DNA had alanine transaminase (ALT) or aspartate transaminase (AST) within normal limits, and none had an investigator-reported AE of hepatitis.

HBV serology and DNA detectability in patients treated with baricitinib in Phase 3 trials

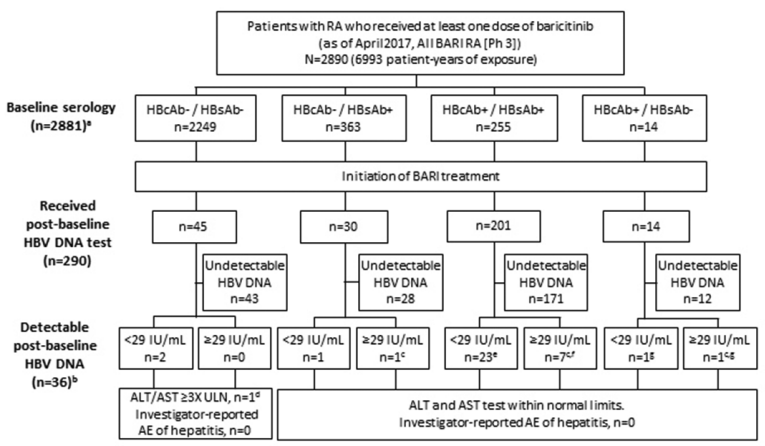

Total number of patients with baseline serology is $n=2881$ due to missing data for 9 patients $(8$ missing surface antibody and

Patients with detectable post-basel ine HBV DNA were from China (11), Japan (9), Taiwan (6), Israel (2), Greece (2), Russia (2). United States (2), Argentina (1), and South Korea (1).

Nine patients had quantifiable HBV DNA levels of $31,36,60,76,92,256,257,869$, and $1547 \mathrm{IU} / \mathrm{m}$

Patient with ALT/AST 23xULN was discontinued from study due to abnormal liver function test. Patient had a single asel ine Hov DiA

ine HBV DNA not detected.

Abreviations: AE=adverse event, ALT=alanine transaminase, AST=aspartate transaminase, BARI=baricitiniti, $H B C A b=h e p a t i t i s ~ B$ virus core antibody, HBsAb=hepatitis B virus surface antibody, HBV=hepatitis B virus,

Abstract FRI0077 - Figure 1. HBV serology and DNA detectability in patients treated with baricitinib in Phase 3 trials

Conclusions: Approximately $12 \%$ of BARI-treated pts with prior HBV infection later tested HBV DNA+ (3\% were above the LLD), although no pts developed clinical evidence of hepatitis and in most cases antiviral therapy was not used.

\section{REFERENCES:}

[1] Chen MH, et al. J Infect Dis 2017;215(4):566-73.

[2] Chen YM, et al. JMII 2017.

Disclosure of Interest: M. Harigai Grant/research support from: BristolMyers Squibb K.K., Eisai Co., Ltd., Ono Pharmaceuticals, and Takeda Pharmaceutical Co., Ltd, Consultant for: Eli Lilly and Company, K. Winthrop Grant/research support from: Pfizer, BMS, Consultant for: Pfizer, UCB, Abbvie, Eli Lilly and Company, Amgen, BMS, T. Takeuchi: None declared, T.-Y. Hsieh: None declared, Y.-M. Chen: None declared, J. Smolen Grant/research support from: AbbVie, Janssen, Eli Lilly and Company, MSD, Pfizer, Roche, Consultant for: AbbVie, Amgen, 
Astra-Zeneca, Astro, BMS, Celgene, Celltrion, Chugai, Gilead Glaxo, ILTOO, Janssen, Eli Lilly and Company, Medimmune, MSD, Novartis-Sandoz, Pfizer, Roche, Samsung, Sanofi-Aventis, UCB, G. Burmester Consultant for: Eli Lilly and Company, C. Walls Shareholder of: Eli Lilly and Company, Employee of: Eli Lilly and Company, W.-S. Wu Shareholder of: Eli Lilly and Company, Employee of: Eli Lilly and Company, C. Dickson Shareholder of: Eli Lilly and Company, Employee of: Eli Lilly and Company, R. Liao Shareholder of: Eli Lilly and Company, Employee of: Eli Lilly and Company, M. Genovese Grant/research support from: Eli Lilly and Company, AbbVie, Consultant for: Eli Lilly and Company, AbbVie, DOI: 10.1136/annrheumdis-2018-eular.1935

\section{FRI0078 PROSPECTIVE FOLLOW-UP OF A COHORT OF PATIENTS WITH INTERSTITIAL LUNG DISEASEASSOCIATED WITH RHEUMATOID ARTHRITIS IN TREATMENT WITH DMARD}

N. Mena-Vázquez ${ }^{1}$, C. Gomez-Cano ${ }^{2}$, L. Perez-Albaladejo ${ }^{3}$, S. Manrique-Arija ${ }^{1}$, C. Romero-Barco ${ }^{4}$, C. Aguilar-Hurtado ${ }^{5}$, I. Ureña-Garnica ${ }^{6}$, F. Jiménez-Núñez ${ }^{1}$ M. Ordóñez-Cañizares ${ }^{1}$, C. Fuego ${ }^{1}$, M. Padin-Martin ${ }^{5}$, R. Caliz-Caliz ${ }^{3}$,

A. Fernández-Nebro. . ' UGC de Reumatología, Instituto de Investigación Biomédica de Málaga (IBIMA) Hospital Regional Universitario de Málaga, Universidad de Málaga., Málaga; ${ }^{2}$ Department of Rheumatology, Hospital Virgen de Valme, Sevilla; ${ }^{3}$ Department of Rheumatology Hospital Virgen de las Nieves. Granada; ${ }^{4}$ UGC de Reumatología, Instituto de Investigación Biomédica de Málaga (IBIMA), Hospital Clínico Virgen de la Victoria, Universidad de Málaga; ${ }^{5}$ Department of Radiology Hospital Regional de Málaga; ${ }^{6}$ Department of Rheumatology at the University Regional Hospital of Malaga (HRUM). Institute for Biomedical Research in Malaga (IBIMA). Malaga University, ${ }^{7}$ UGC de Reumatología, Instituto de Investigación Biomédica de Málaga (IBIMA) Hospital Regional Universitario de Málaga, Departamento de Medicina y Dermatología, Universidad de Málaga., Málaga, Spain

Objectives: To describe prospectively the evolution of interstitial lung disease (ILD) in RA treated with modifying antirheumatic drugs (DMARDs) in clinical practice.

Methods : Design: Multicenter prospective observational cohort. Patients: Patients with RA (ACR/EULAR 2010 criteria) and ILD (American Thoracic Society) from different centres of Málaga, Valme Hospital of Sevilla and Virgen Nieves of Granada were included. Protocol: All patients with RA and ILD who visited clinic from 2015 to 2017 were recruited. They were reviewed according to a predetermined protocol for data collection. Resolution Computed Tomography (HRCT), Pulmonary function test (PFT) and echocardiogram were requested for all patients who did not have it in the last year. This visit was marked as v0 (index date). At 12 months (v12) the joint assessment (DAS28), echocardiogram, PTF and HRCT were again evaluated. HRCT's were assessed by the same radiologist. Outcomes: At v12:( ${ }^{1}$ improvement (ie improvement in FVC $\geq 10 \%$ or DLCO $\geq 15 \%$ and no radiological progression), ${ }^{2}$ non-progression (stabilisation or improvement in FVC $\leq 10 \%$ or DLCO $<15 \%$ and no radiological progression), ${ }^{3}$ progression (worsening of FVC $>10 \%$ or DLCO $>15 \%$ and radiological progression), or $^{4}$ death due to ILD. Variables: Description of ILD type and lung function by PTF, HRCT. Presence of PTH by echocardiogram and dyspnoea. Disease activity by DAS28-ESR;Adverse events during the follow-up period. Statistical analysis: Descriptive analysis and Wilcoxon or T test between the v0 and v12. One factor ANOVA between SDMARD, bDMARD and combination therapy groups.

Results: The main characteristics at $\mathrm{V} 0$ of the patients $(n=41)$ are shown in the table 1 . Nine patients $(21.9 \%$ ) received a sDMARDs with a bDMARDs;25 patients $(60.9 \%)$ monotherapy with sDMARD and $7(17.0 \%)$ monotherapy with bDMARDs (table 1). Nine patients (21.9\%) had improvement (2 with MTX, 1 with MTX $+\mathrm{HCQ}$, 2 with RTX, $2 \mathrm{HCQ}+\mathrm{RTX}, 1 \mathrm{MMF}+\mathrm{RTX}$ and 1 with $\mathrm{ABA}) ; 24$ patients $(58.5 \%)$ remained stable ( 6 with MTX, 6 with LFN, 3 with HCQ, 1 AZA, 1 SSZ, 1 MMF, 1 TCZ, 2 ABA, $1 \mathrm{MTX}+\mathrm{ETN}, 1 \mathrm{HCQ}+\mathrm{RTX}, 1 \mathrm{HCQ}+\mathrm{ADA}, 1 \mathrm{RTX}+\mathrm{MMF})$; and 7 $(17.0 \%)$ got worse of ILD (2 with MTX developed lung nodules not known, 2 with LFN, 1 with LFN +IFX, 1 with ETN +MTX and 1 with SSZ). One patient died due to respiratory infection (with RTX). Two patients developed PPH. We did not find significant differences between Vo DAS28 and v12 (2.61 [0.74] vs 2.54 [1.12]; $\mathrm{p}=0.684)$ or in $\mathrm{HAQ}(1.12[0.89]$ vs $1.23[0.73], \mathrm{p}=0.368)$. There were no significant differences in PTF, HRCT or DAS28 between SDMARD, bDMARD and combination therapy groups. During the follow-up period 27 patients had infections, the majority $(53.7 \%)$ respiratory infection.

\begin{tabular}{|c|c|}
\hline VARIABLES & Patients \\
\hline Sex (male), $n(\%)$ & $21(51.2)$ \\
\hline Age (years), mean (DE) & $67.9(7.8)$ \\
\hline Smoker, n (\%) & $8(19,5)$ \\
\hline Ex-smoker, n(\%) & $32(78)$ \\
\hline Body mass index (BMI), mean (SD & $28.7(5.3)$ \\
\hline Disease duration (months), median ( $p 25-p 75$ ) & $138.1(77.7-285.3)$ \\
\hline ILD duration (months), median (p25-p75) & $41.4(10.1-79.2)$ \\
\hline Rheumatoid factor, $\mathrm{n}(\%)$ & $39(95.1)$ \\
\hline Anti-cyclic citrullin ated peptide, $n(\%)$ & $35(85.4)$ \\
\hline Erosions, n (\%) & $27(66)$ \\
\hline DAS28, mean (DE) & $2.8(0.8)$ \\
\hline$H A Q$, mean (DE) & $1.2(0.8)$ \\
\hline \multicolumn{2}{|l|}{ Treatment } \\
\hline sDMARD, $n(\%)$ & $34(82.9)$ \\
\hline Methotrexate, $n(\%)$ & $13(31.7)$ \\
\hline Leflunomide, $n(\%)$ & $9(22.0)$ \\
\hline Sulfasalazine, $n(\%)$ & $2(4.9)$ \\
\hline Hydroxychloroquine, $n$ (\%) & $6(14.6)$ \\
\hline Azathioprine & $1(2.4)$ \\
\hline Micofenolato & $3(7.3)$ \\
\hline MTX+HQC & $2(4.9)$ \\
\hline bDMARDs, n (\%) & $16(39.0)$ \\
\hline Rituximab, $n(\%)$ & $7(17.1)$ \\
\hline Abatacept, $\mathrm{n}(\%)$ & $3(7.3)$ \\
\hline Etanercept, $n(\%)$ & $3(7.3)$ \\
\hline Infliximab, n (\%) & $1(2.4)$ \\
\hline Adalimumab, $\mathbf{n}(\%)$ & $1(2.4)$ \\
\hline Tocilizumab, $n(\%)$ & $1(2.4)$ \\
\hline
\end{tabular}

Conclusions: Most patients with RA and ILD who are receiving treatment with DMARD $(80.5 \%)$ remained stable or improved after at least one year of both synthetic and biological DMARD treatment. More prospective studies are necessary to identify the influence of DMARDs in this evolution.

Disclosure of Interest: None declared

DOI: 10.1136/annrheumdis-2018-eular.4100

\section{FRI0079 ADIPONECTIN LEVEL, INSULIN RESISTANCE, ENDOTHELIAL DYSFUNCTION IN FEMALES WITH RHEUMATOID ARTHRITIS AND COMORBID HYPERTENSION}

O. Sirenko, O. Kuryata, T. Lysunets. State Establishment «Dnipropetrovsk medical academy of Health Ministry of Ukraine», Dnipropetrovsk, Ukraine

Background : Rheumatoid arthritis (RA) associates with accelerated atherosclerosis and high cardiovascular mortality. Cardiovascular risk assessment in RA pts with comorbid hypertension (HT) is do not fully reflected by traditional risk scales, thus additional factors searching is required.

Objectives: We aimed to estimate the adiponectin level, insulin resistance, endothelial function in RA females with comorbid $\mathrm{HT}$ and its relationship with subclinical manifestations of atherosclerosis.

Methods: The study included 82 RA females with low disease activity and comorbid HT (mean age of 54.6 [49.7; 62.5] years) and $40 \mathrm{HT}$ females without RA (control group). All pts received stable therapy of RA more than 6 months. Pts with coronary artery disease were excluded. The risk of fatal cardiovascular disease was calculated using mSCORE. RA disese activity was measured using DAS28 scale. Carotid ultrasound detection and endothelial-dependent flow mediated vas odilatation (EDVD) by Celermajer method were performed. The levels of adiponectin, insulin were measured using ELISA kit test, insulin resistance was estimated using HOMA2 index.

Results: Endothelial dysfunction was established in the majority of main group patients - $61(74.4 \%)$, insulin resistance - in 70 (85.4\%), elevated levels of adiponectin - in 35 (42.7\%). Hypertensive females with RA had significantly higher adiponectin, insulin, insulin resistance levels compare to control $(p<0.05)$. Subclinical manifestations of atherosclerosis were established in 64 (78.0\%) HT females with RA and 10 (50\%) control group pts. While the median cardiovascular risk level was $4.2[2.7 ; 6.5] \%$ matched by mSCORE. The presence of atherosclerotic plaques in $\mathrm{HT}$ females with $\mathrm{RA}$ was associated with age $(\mathrm{OR}=1.242, \mathrm{p}=0.004$ $95 \% \mathrm{Cl} 1.007-1.78)$, glucocorticosteroid therapy $>3$ months $(\mathrm{OR}=1.56, p=0.001$ $95 \% \mathrm{Cl} 1.22-2.45)$, endothelial dysfunction $(\mathrm{OR}=3.584, \mathrm{p}=0.001,95 \% \mathrm{Cl} 1.71-$ 4.723), insulin resistance ( $O R=1.684, p=0.011,95 \% \mathrm{Cl} 1.22-2.74)$, abnormal adiponectin level $(O R=1.71, p=0.028,95 \% \mathrm{Cl} 1.17-2.43)$. AUROC index for prognostic role of adiponectin and HOMA2 in subclinical atherosclerosis develop were 0.79 (95\% Cl 0.64-0.95; $\mathrm{p}<0.05$ ) and 0.76 (95\% Cl 0.61-0.92; $\mathrm{p}<0.05$ ) respectively, that indicate a good quality of diagnostic models. 